\title{
Como receber o outro: a escuta psicanalítica na clínica extramuros ${ }^{1}$
}

\author{
Susana Muszkat ${ }^{2}$ \\ Iliana Horta Warchavchik \\ Maria Augusta Gomes
}

A atual diretoria da SBPSP vem dando ênfase à clínica extramuros ou clínica extensa (Herrmann, 2005)), em que a escuta e atuação psicanalíticas se ampliam para além da clínica padrão em seu enquadre da clínica individual, evidenciando sua potência metodológica em distintos dispositivos.

Psicanálise e suas clínicas é a tradução desta prática plural, onde nos propomos a conversar com Outros, em dispositivos variados, aprendendo seus idiomas, ou frequentando seus territórios, num deslocamento que flexibiliza as fronteiras entre a psicanálise e as múltiplas áreas de interação.

Kaës (1991) propõe uma "afinidade conflituosa entre grupo e psicanálise", afirmando que a “'questão do grupo' está introduzida na psicanálise desde sua origem, constituindo-se na matriz fecunda e traumática da invenção da psicanálise, de sua instituição e de sua transmissão". (p.25)

Desta forma, a clínica extramuros recupera as origens do pensamento psicanalítico.

Constituímo-nos em relações de intersubjetividade, sempre inseridos num campo grupal. Assim, nossa subjetivação se dá na pluralidade, somos um composto de muitos, cada um em sua condição de singularidade. A psicanálise como campo teórico e clínico, também se constitui a partir de interlocuções intersubjetivas.

O grupo como representante e integrante da Instituição carrega em si tanto o potencial singular de cada indivíduo que o compõe sendo um lugar de pertencimento e proteção de afinidades identitárias, como também contem aspectos conservadores, violentos, hierárquicos em maior ou menor grau, característico das Instituições. Esses aspectos, dependendo do grau de (in)flexibilidade de sua organização, podem dissolver as

\footnotetext{
${ }^{1}$ Este trabalho foi apresentado na mesa "Como receber o outro " com José Moura Gonçalves Filho no eixo "Psicanálise e suas clinicas" no I Simpósio Bienal "O mesmo, o outro: Psicanálise em movimento" da Sociedade Brasileira de Psicanálise de São Paulo.

${ }^{2}$ Membro efetivo e docente da SBPSP e Coordenadora do Centro de Atendimento Psicanalítico da SBPSP
} 
características singulares de seus membros, na direção de uma massa homogênea destituída de pensamento crítico e criativo e, principalmente, sem condição de exercerem-se enquanto sujeitos de desejo e originalidade.

Freud em 1921 já descrevia o fenômeno:

É lícito dizer que as fartas ligações afetivas que vemos na massa bastam inteiramente para explicar uma de suas características, a falta de autonomia e de iniciativa de cada indivíduo, a similitude entre a sua reação e a de todos os demais, seu rebaixamento a indivíduo de massa, por assim dizer. (P. 77)

Instituições, tal qual famílias são: lugar de acolhimento e proteção, estruturação, pertencimento.

Sendo uma família tendendo ao saudável, garantirá espaço de crescimento a seus membros, tolerando inclusive movimentos transgressivos e/ou questionadores como elementos de conquista e crescimento.

Por outro lado, Instituições ou famílias em que as normas, regras, sistemas hierárquicos, fronteiras, sejam muito inflexíveis, impermeáveis, são famílias/ instituições que adoecem.

Novamente em Kaës (1991): “as instituições, assim como as civilizações por elas sustentadas, não são imortais. A ordem que impõem não é imutável, os valores que proclamam são contraditórios e elas negam aquilo que lhes serve de base”. (p.4)

Desta forma, não podemos nos furtar a questionar essas mesmas Instituições, sob o risco de ficarmos obsoletos, isolados do contexto social e decretarmos assim, nosso lento, mas certeiro desaparecimento.

A questão que nos é colocada nessa Bienal está posta da seguinte forma: "Como receber o outro?

Bem, podemos num primeiro impulso responder que sendo psicanalistas é isso que fazemos! Recebemos outros com sofrimentos de ordem diversas. Parece obvio, natural. 
O encontro com o Outro, ou podemos dizer, o encontro de Outros, impõe um deslocamento de si, um deslocamento do lugar familiar. O outro na condição de sujeito diferente de mim, em sua condição inabarcável de alteridade radical me retira e ameaça da condição familiar e protegida.

Há uma permanente tensão, inversamente proporcional, entre a potência da homogeneidade da massa e a força criativa dos sujeitos que a compõe. Se prevalecerem as forças individuais, o grupo se dissolve. Por outro lado, se as características de massa eliminarem completamente os sujeitos, a Instituição adoece, assim como seus membros.

Sujeito e Instituição se colocam desta maneira em posição de conflito dialético.

Quem é o Outro que nos chega?

Invariavelmente o Outro nos é um desconhecido. E se nos dispusermos a recebe-lo é da essência da prática psicanalítica que, nos esforcemos ao máximo para recebe-lo da forma como vier, com o que lhe for próprio.

Vale lembrar que o outro eixo dessa Bienal é o analista desconcertado. Desconcertado com o desconhecido do outro e também com o que do outro me invoca a relacionar-me com aquilo em mim que desconheço ou recuso. Desta forma, os dois eixos são indissociáveis enquanto questão: o desconcerto é intrínseco ao ato de receber um outro.

Partilho aqui as ideias de Márcio Giovannetti (2005) - em seu trabalho sobre a Hospitalidade na clínica psicanalítica- que, citando Derrida descreve a desejada e talvez utópica postura da escuta psicanalítica:

Mas a hospitalidade pura ou incondicional não consiste em tal convite ("Eu o convido, eu dou-lhe as boas vindas ao meu lar, sob as condições que você se adapte às leis e normas do meu território, de acordo com a minha linguagem, tradição, memória, etc.”). A hospitalidade pura e incondicional, a hospitalidade em si, abre-se ou está aberta previamente para alguém que não é esperado nem convidado, para quem quer que chegue como um visitante absolutamente estrangeiro, como um recém-chegado, não identificável e imprevisível, em suma, totalmente um outro... mas será que uma hospitalidade sem risco, uma hospitalidade apoiada em certas garantias, protegida por um sistema imune contra o totalmente outro, seria uma hospitalidade verdadeira? (Giovannetti, 2005, citando Derrida, Filosofia em tempos de terror). 


\section{O Encontro das Instituições}

Fomos procurados por uma instituição pública que, em função do tipo de trabalho exercido enfrentava tanto interna quanto externamente situações de violência e de grande desgaste emocional. Consequentemente, havia um alto índice de adoecimento de seus funcionários resultando em número significativo de afastamentos, licenças médicas e pedidos de transferência para outros setores. Propusemos encontros em grupos.

O trabalho que resultou no livro Violência e Masculinidade (Muszkat, S., 2011) coordenando grupos de reflexão com homens em situação de violência familiar, serviu de norteador para adotar esta linha de trabalho com os funcionários públicos.

Propusemos grupos formados com aproximadamente 12 integrantes, além das 3 analistas coordenadoras, com 8 encontros de $1 \mathrm{~h} 30$ cada um.

\section{O quarto de despejo e os interstícios segundo Roussillon}

Roussillon (1991), psicanalista francês, propõe os conceitos de quarto de despejo e espaços intersticiais como lugares de destino dos aspectos não passíveis de serem contidos pela Instituição.

Assim, o quarto de despejo é definido como um espaço cuja função é a de dar um destino aos resíduos e restos excessivos, não passíveis de simbolização na instituição. Esse trabalho, pode tanto ser exercido através de algum tipo de reunião com esse objetivo ou ainda, por uma pessoa que "encarne" essa função na instituição.

A necessidade de reconhecimento e criação de tal espaço de 'tratamento' e elaboração destes resíduos implica certo sacrifício de tempo do trabalho sendo, portanto, importante um consenso quanto a existência e a escolha de um espaço-tempo para realizá-lo. O trabalho de instauração deste espaço é um processo de elaboração e constituição permanentes, que vêm se dando ao longo das conversas que vimos tendo nos distintos grupos que atendemos.

Os espaços intersticiais são espaços institucionais comuns a todos os lugares de passagem: os intervalos, cafezinhos, folgas comuns onde se dão as "conversas de 
corredor", promovendo uma circulação desses resíduos; é a passagem do mundo exterior para o interior e vice-versa.

O dito e feito aqui, apresenta uma latência de sentidos, uma ambiguidade quanto a seu caráter de lugar privado ou espaço de trabalho. Em alguns casos, o grau elevado de angustia pode resultar em organizações do tipo congelamento, segredo ou enquistamento ou ainda, a clivagem em estado de cripta, produzindo os sintomas do grupo.

Acreditamos que funcionamos um pouco como esses dois espaços, o quarto de despejo e o espaço intersticial. Percebemos que, a possibilidade de encontros e trocas antes e depois das reuniões propriamente ditas, são aproveitados e muito valorizadas por eles. Numa ocasião, por exemplo, quando da suspensão de um dos encontros, dois membros do grupo que não haviam visto a mensagem, vieram e ficaram conversando e 'se conhecendo' durante todo o tempo reservado para nossos encontros. $\mathrm{O}$ relato posterior merece ser destacado, onde ressaltaram o prazer desta experiência de trocas interpessoais, de algo mais íntimo que se viabilizou por este tipo de espaço.

\section{O Grupo ao vivo}

A referência ao mecanismo por eles nomeados de rolo compressor alude ao apagamento das características individuais dos membros da Instituição. "Se a pessoa tenta ser diferente, defender sua posição, o rolo passa de novo. Uma solução é ficar no canto pra o rolo não passar".

Segundo eles, a condição ou a tentativa de se manifestar enquanto sujeitos com ideias diferentes das já tradicionalmente em prática, têm como resposta de seus superiores a adoção de medidas vividas invariavelmente como punições. São medidas que dificultam ora a vida profissional, ora a vida pessoal e/ou familiar do servidor. A consequência destas medidas/punições são, não raro, os pedidos de afastamento, os frequentes atestados de licença médica, ou o franco adoecimento físico ou psicológico como depressão, alcoolismo, drogadição, violência e, até mesmo suicídio.

De nossa parte, o cuidado permanente é o de não submergirmos na vivência rolo compressor, do 'não tem jeito mesmo', ficando identificadas com os 'filhos desamparados e quase órfãos' em situações de trabalho injustas e desumanas. 
Ao mesmo tempo que nossa escuta é necessária como testemunho e validação do submetimento a eles imposto, nosso esforço permanente é o de abrir brechas para novas narrativas, estimular a troca entre eles, apontando aberturas nas contradições que aparecem durante as conversas.

"Aqui podemos falar o que pensamos e não falar o que as pessoas querem ouvir. Não precisamos falar para agradar, podemos nos expor sem medo".

Ou ainda, "aqui é um espaço pra falar a verdade"; e mais "recebemos sempre um conselho que tem como objetivo não mudar nada. Ouça os antigões que vai dar tudo certo. Temos que arriscar, temos que pensar numa fração de segundos como fazem os jogadores de futebol. Qualquer mudança tem que partir de nós”.

“Escutar produz mudanças” diz Janine Puget. (p.29)

“É preciso de espaço de escuta para poder lidar com a dor", diz Isabel Khan em recente aula na SBPSP.

Ainda Puget, " ser testemunha é um dos componentes da função analítica. Se trata por vezes de dar testemunho - validar, reconhecer a existência e o acontecido- e outras de tentar ajudar a transformar uma testemunha impotente ou vitimizada em testemunhas capazes de dar seu testemunho tecendo novas histórias”. (p.159)

Poderá uma escuta diferente mudar o contexto subjetivo?

Uma escuta ativa desloca o grupo de seu lugar conhecido e adaptado forçando à reflexão e o olhar sobre si a partir do olhar de um outro, vindo de 'outra família', outra instituição.

O estrangeiro, o visitante de fora provoca mudanças de lugares. Há sempre o risco de que se os lugares instituídos forem muito inflexivelmente determinados, ou se os estrangeiros forçarem sua entrada de maneira muito vigorosa, estes sejam expelidos, expulsos pela ameaça que provocam. Esses estrangeiros podemos ser nós.

Mas, há as trocas entre eles - sustentadas por nós, analistas-, quando falam de vivências de perdas, lutos, dores, aposentadoria, evidenciando a função de rede de apoio emocional do grupo. Algumas vezes a percepção desta função possível na atividade de grupo, levou alguns participantes a proporem formatos similares em suas próprias 
equipes de trabalho. Em outras, levou a que indicassem o desejo de continuar essas reflexões num trabalho de análise.

Hoje, 2 anos após o início deste trabalho, podemos ter como hipótese que, o marcado sentimento persecutório despertado repetidamente a cada início de um novo grupo, pode ser a reprodução, na transferência conosco, da vivência do modelo punitivo praticado de maneira vertical na Instituição. Ultimamente, os grupos têm vindo menos perseguidos. Ainda intrigados, mas menos perseguidos. Ousaríamos dizer que, por um lado, nos tornamos mais familiares como ideia na Instituição e, por outro, fomos consolidando o lugar de coordenadoras junto a eles e entre nós, em sintonia de trabalho.

Em suma, o trabalho de grupo vem propiciando que os elementos rejeitados, não reconhecido na estrutura institucional encontrem expressão e continência num lugar protegido para posteriormente poderem ser retomados. E ainda, este processo com os diversos elementos aqui abordados, tem, como potencial, a semente necessária para a condição de expressarem-se enquanto sujeitos singulares, o que de nosso ponto de vista será um fator essencial para a reversão do adoecimento institucional. E é nesse sentido que nosso trabalho como espaço do quarto de despejo, se oferece como lugar onde tensões intra e inter-grupais, possam ganhar expressão, prevenindo a invasão da violência atuada, para que o restante do funcionamento institucional seja preservado de atuações.

\section{Referências}

Freud, S. (2011). Psicologia das Massas e análise do eu. In Paulo César de Souza (trad.), Psicologia das Massas e análise do eu e outros textos. (1920-1923). São Paulo: Companhia das Letras. (Trabalho original publicado em 1912-1913).

Giovannetti, de F, M. (2005). Hospitalidade na clínica psicanalítica hoje. In: Revista Brasileira de Psicanálise: 39(4): 25-32. 
Herrmann, F. (2005). Clínica Extensa, In:A Psicanálise e a Clínica Extensa. São Paulo: ed. Casa do Psicólogo.

Kaes, R. (1991), Realidade psíquica e sofrimento nas instituições, In: A Instituição e as Instituições: Estudos Psicanalíticos, Kaes, R; Bleger, J; Enriques, E; Fornari, F; Fustier, P; Rousillon, R; Vidal, J.P. São Paulo: Casa do Psicólogo.

Marin, K. da S. I. (2018). In: comunicação oral em aula na Sociedade Brasileira de Psicanálise de São Paulo.

Muszkat, S. (2011) Violência e Masculindade. São Paulo: Editora Casa do Psicólogo

Puget, J.(2015). Subjetivación descontínua y psicoanálisis: incertidumbre y certezas. Buenos Aires: Editora Lugar Editorial

Rousillon, R. (1991). Espaços e práticas institucionais- quarto de despejo e o interstício. In: A Instituição e as Instituições: Estudos Psicanalíticos, Kaes, RC; Bleger, J; Enriques, E; Fornari, F; Fustier, P; Rousillon, R; Vidal, J.P. São Paulo: Casa do Psicólogo. 